Discussion Paper No. 786

\title{
DECEPTION AND CONFESSION: \\ EXPERIMENTAL EVIDENCE \\ FROM A DECEPTION GAME IN JAPAN
}

\author{
Keiko Aoki \\ Kenju Akai \\ Kenta Onoshiro
}

\begin{abstract}
August 2010
The Institute of Social and Economic Research

Osaka University

6-1 Mihogaoka, Ibaraki, Osaka 567-0047, Japan
\end{abstract}




\title{
Deception and confession:
}

Experimental evidence from a deception game in Japan

\author{
Keiko Aoki* \\ Institute of Social and Economic Research, Osaka University \\ Kenju Akai \\ Institute of Social and Economic Research, Osaka University
}

Kenta Onoshiro

Graduate School of Economics, Osaka University

\begin{abstract}
This study investigated lying behavior and the behavior of people who are deceived by using a deception game (Gneezy, 2005) in both anonymity and face-to-face treatments. Subjects consist of students and non-students (citizens) to investigate whether lying behavior is depended on socioeconomic backgrounds. To explore how liars feel about lying, we give senders a chance to confess their behaviors to their counter partner for the guilty aversion of lying. The following results are obtained: i) a frequency of lying behavior for students is significantly higher than that for non-students at a payoff in the anonymity treatment, but that is not significantly difference between the anonymity and face-to-face treatments; ii) lying behavior is not influenced by gender; iii) a frequency of confession is higher in the face-to-face treatment than in the anonymity treatment; and iv) the receivers who are deceived are more likely to believe a sender's message to be true in the anonymity treatment. This study implies that the existence of the partner prompts liars to confess their behavior because they may feel remorse or guilt.
\end{abstract}

Key words: deception game, lying behavior, experiment, face-to-face, anonymity, confession

\footnotetext{
Corresponding author. E-mail: k_aoki@iser.osaka-u.ac.jp. Address: Institute of Social and Economic Research, Osaka University, 6-1 Mihogaoka, Ibaragi, Osaka 567-0047, Japan.
} 


\section{Introduction}

Fraud is practiced around the world, and the monetary losses are tremendous. For example, losses in the United States and Japan were approximately 560 and 307 million dollars in 2009, respectively. ${ }^{1}$ Losses can never be totally eliminated, though they may increase or decrease due to policy implementation and efforts of the police. Why do people practice deception? Several studies on this question in order to help to prevent offenses before they happen as well as repeat them are investigated in experimental economics as well as social psychology. ${ }^{2}$

For example, Boles et al. (2000) defined deception as the transmission of information and investigated the dynamics of deception and retribution in a repeated ultimatum game. They found that proposers and responders chose deceptive strategies almost equally, though proposers told more outright lies. Brandts and Charness (2002) defined deception as an action different from the message one player sent about an intended play in a game. They also investigated willingness to punish an unfair action based on whether the action was preceded by a deceptive message. They found that false messages lead to punishment much more frequently than do accurate messages. Croson et al. (2003) defined deception as misrepresentation of the relative size of an outside option or the amount either player wrote in a sent message. They investigated the impact of cheap talk in an ultimatum bargaining setting with two-sided imperfect information. They found that lies about private information influences bargaining outcomes (offers and responses) in both the short- and long-term. In these studies, deception was considered a tool of negotiation in a bargaining game.

On the other hand, Gneezy (2005) developed a deception game, which is a cheap talk game between a sender and a receiver and found that some senders told a lie when they could receive more of a payoff with three times the difference between stakes. His results could provide an insight into why people deceive as well as reasons for not telling a lie, such as feeling guilty about lying or having an aversion to lying (Gneezy, 2005; Hurkens and Kartik, 2009; Lundquist et al., 2009). Sutter (2009) tried to classify even telling the truth as deception if the sender chooses a true message with the expectation that the receiver will not follow the sender's message. He used the deception game and confirmed this definition of deception under team decision making, not individual type. Hurkens and Kartik (2009) reinterpreted the evidence on lying and deception presented in Gneezy's results by adding strategy methods and different monetary payoffs in a within-subjects design. They confirmed Gneezy's finding that there is a statistically significant level of lying aversion. With regard to how this aversion to lying varies with consequences, however, they could not show that the decision to lie was independent of how much a subject gained and how much

\footnotetext{
${ }^{1}$ See the Crime Complaint Center for U.S. data at http://www.ic3.gov/media/2010/100312.aspx and the National Police Agency for data on Japan at http://www.npa.go.jp/hakusyo/h21/index.html

2 There are the several psychological studies on deception: An introduction to the psychology of deceit (Ford, 1995); Taxonomy of lies and their classifications according to content, motivation, and magnitude (DePaulo et al., 1996); how to detect lies (Ekman, 1992; Vrij, 2001)., etc.
} 
the partner lost as long as he/she preferred the outcome from lying.

This study investigates lying behavior and the behavior of people who are deceived using a deception game with both anonymity and face-to-face treatments. Subjects consist of students and non-students to investigate robustness of lying behavior from the viewpoint of various socioeconomic backgrounds. Although the above mentioned studies focus on anonymous condition, only Holm and Kawagoe (forthcoming) investigated lying behavior in the face-to-face treatment by using a called bluffing game. However, in order to investigate whether the difference of anonymity affect lying behavior, we conduct the experimental deception game in the directly meeting face-to-face condition as well as anonymity. Apart from the deception game, the face-to-face condition has mainly two methods. One is that players meet directly, allowing decision making to be influenced by the counterpart's appearance, such as face and physique (Frohlich and Oppenheimer, 1998; Isaac and Walker, 1988; Brosig et al., 2003; Bochet et al., 2006). ${ }^{3}$ The other is that subjects provide personal information such as name and gender, thereby possibly confounding results (Roth, 1995; Bohnet and Frey, 1999; Charness and Dufwenberg, 2006; Charness and Gneezy, 2008).

Moreover, we explore how liars feel about their lying behavior. We give only senders a chance to send a message with respect to their behavior to their counter partners after the game. These messages were developed based on three kinds of liars' emotions corresponding to lying behavior, i.e., fear of being caught, deception guilt, and duping delight in social psychology (Ekman and Friesen, 1969; Ekman, 1992). ${ }^{4}$ In this study, fear of being caught was indicated by not sending any message. Deception guilt was demonstrated by message i) I told a lie. I am sorry, and message ii) I told a lie because there were reasons. Duping delight was shown by message iii) I told the truth, and message iv) I told the truth. Please trust me. With respect to studies on the apology, ${ }^{5}$ they are reportedly used to rebuild damaged interactions (Ho, 2007; Abeler et al., 2010; Fischbacher and Utikal, 2010) and repair trust (Gibson et al., 1999; Bottom et al., 2002; Kim et al., 2004; Schweitzer et al., 2006), for example. ${ }^{6}$ Compared with those studies, this study focused on voluntary confessions, which included the liars' justification as well as an apology. We consider justification to be a kind of guilt that leads to liars revealing their behavior voluntarily.

The following results are obtained: i) a frequency of lying behavior for students is

\footnotetext{
3 All researchers conducted a public goods game. Frohlich and Oppenheimer (1998) found significantly less cooperation with e-mail communication than with face-to-face communication. Isaac and Walker (1988) found free form face-to-face communication especially effective in increasing contributions and efficiency. Brosig et al. (2003) found that level and stability of cooperation in pre-play face-to-face communication using visual and auditory information were higher than in nonverbal and either visual or auditory communications. Bochet et al. (2006) found that pre-play face-to-face treatment raised contributions relative to treatments that were not face-to-face.

${ }^{4}$ Ekman (1992) found that these emotions are felt by real criminals as well.

${ }^{5}$ In the economics literature, fear corresponds to the risk of consumption in an economic system (Turvey et al., 2010) and to investment in assets (Hwang, 2006), for example. For a relevant study in the psychology literature, see Ekman et al. (1988). On the other hand, there are very few economic studies regarding duping delight (see Ekman, 1989).

${ }^{6}$ See 2. Related Literature (pp. 3) in Fischbacher and Utikal (2010), which provides psychological studies on apology in detail.
} 
significantly higher than that for non-students at a payoff in the anonymity treatment, but that is not significantly difference between the anonymity and face-to-face treatments; ii) lying behavior is not influenced by gender; iii) a frequency of confession is higher in the face-to-face treatment than in the anonymity treatment; and iv) the receivers who are deceived are more likely to believe a sender's message to be true in the anonymity treatment.

The remainder of the paper is organized as follows. Section 2 explains the designs of the experiment. Section 3 presents empirical models and hypotheses. Section 4 presents results and Section 5 draws the conclusion.

\section{Experimental design and procedures}

\subsection{Design}

We follow deception game developed by Gneezy (2005). There are two players; a sender and receiver. Only the sender is informed about the monetary payoffs of two different options, A and B, as follows:

Option A: $\mathrm{X}$ yen to you and $\mathrm{Y}$ yen to the other student

Option B: Y yen to you and X yen to the other student

In Gneezy, $\mathrm{X}$ and $\mathrm{Y}$ consisted of several monetary payoffs. The sender's only choice in this game was to send one of the following two messages to the receiver:

Message A: "Option A will earn you more money than Option B."

Message B: "Option B will earn you more money than Option A."

The receiver reads the sent message and has to choose one of the two options implemented for payment. After his decision, the receiver is only informed about the monetary payoff from the chosen option. The receiver is not informed about the payoff for the other option or about the sender's payoff in any of the options. Therefore, the receiver cannot judge whether the sender has told the truth either during or after the experiment.

We conducted five treatments, as shown in Table 1 . The anonymity treatment was divided into two groups based on students and nonstudents and by monetary payoffs. ${ }^{7}$ The procedure in this treatment is as above. In the face-to-face treatment, the participant group was students and the

\footnotetext{
7 The stakes were modified from the monetary payoff in Gneezy (2005) where \{Sender: Receiver $\}=\{\$ 5: \$ 6,6 \$$; $\$ 5$ \} because the earnings in this experiment had to be higher than the minimum wage, based on labor laws in Japan.
} 
monetary payoff was 1000 in order to test the treatment effect. ${ }^{8}$ In the face-to-face treatment, Roles A and B stood face to face at a table approximately one meter across in another room. In front of Role B in each pair, Role A chose one of two cards with one of two messages, inserted it into an envelope, and provided it to Role B directly. ${ }^{9}$

Table 1 about here

\subsection{Procedures}

Our procedures were as follows: ${ }^{10}$

Step 1: Participants were gathered in a room before the experiment. An experimenter read aloud a consent form in front of the participants. They were then divided into two rooms by lottery which determined Role A as the sender and Role B as the receiver.

Step 2: The experimenters provided the experimental instruction sheets to participants in each room, and the participants read it. ${ }^{11}$

Step 3: Role A chose one of two cards on which was written either message 1 or 2, inserted it into an envelope, and provided the envelope to the experimenters. The experimenters provided it to Role B in the pair. Next, Role B chose one of two cards on which was written either option A or B, inserted it into an envelope, and provided the envelope to the experimenters.

Step 4: Roles A and B filled out the first questionnaire.

Step 5: Role A was provided the envelope containing the option Role B had chosen. Then, Role A decided whether to send a second message. If Role A decided not to send a second message, Role A did not provide anything to the experimenters. Role B in the pair was not provided any message. On the other hand, if Role A decided to send a second message, Role A chose one of four cards with one of four messages, inserted it into an envelope, and provided the envelope to the experimenters. The experimenters provided it to Role B in the pair.

\footnotetext{
${ }^{8}$ First, we conducted the anonymity treatment to investigate which treatment resulted in the highest percentage of lying. As a result, the highest percentage of lying behavior among abnormity treatments was the A1000-S treatment ${ }^{9}$ It took approximately fifty seconds per pair meeting for Role B to receive the message from Role A. No words were allowed between them during this step.

${ }^{10}$ The detailed instructions for the experiments are in Appendix A. All questionnaires and second messages used in the procedures are shown in Appendices B and C, respectively.

${ }^{11}$ For both senders and receivers, no instructions were written regarding second messages.
} 
Step 6: Role A and the Role B who was sent the second message filled out the second questionnaire firstly and then the final questionnaire. Role B who was not sent any second message filled out the final questionnaire to participate in the same procedure as the others.

Step 7: Participants received a show-up fee (500 JPY) and their earnings in cash privately. The earnings were based on the option Role B chose.

Until Step 3, our procedures are same as Gneezy (2005) ${ }^{12}$. After Step 4, it was extended to add the following two procedures: 1) the sender could send a message (hereafter referred to as the second message) about their lying behavior after the sender was provided the option which the receiver chose; and 2) all of the participants were asked to answer questionnaires on their behavior.

During the procedures above, participants were asked to answer three kinds of questionnaires. As shown in Appendix B.1, the first questionnaire is, at Step 4, for Role A as the sender. There was one question regarding whether Role A expected Role B to believe that the message from Role A was true, as in Gneezy (2005) and Sutter (2009). As shown in Appendix B.2, on the other hand, in the first questionnaire for Role $\mathrm{B}$ as the receiver, there was one question related to whether Role B believed that the message from Role A was true, consistent with Gneezy (2005). In the face-to-face treatment, two questions were added regarding the extent of the acquaintance between partners and their impression of their partner.

The second questionnaire is at Step 6. There were two questions regarding whether Role A sent a second message and the reason Role A sent it. On the other hand, there was one question for only Role B who sent the second message regarding whether Role B believed it to be true.

The third questionnaire is at the end of Step 7. All participants answered questions related to socioeconomic characteristics.

\subsection{Second messages}

The second messages were developed based on liars' emotions, which are known in social psychology (Ekman and Friesen, 1969; Ekman, 1992). There were four different messages, as shown in Appendix C. The relation between the messages and liars' emotions is as follows; The fear of being caught was shown by the decision not to send any message, meaning that liars did not want to reveal their lying behavior to their partners; Deception guilt was demonstrated by message i) I told a lie. I am sorry, and message ii) I told a lie because there were reasons, meaning that liars confessed their lying behavior (Kassin and Gudjonsson, 2004) ${ }^{13}$; and Duping delight was demonstrated by

\footnotetext{
${ }^{12}$ Here we use envelopes as methods such that subjects are not able to see others' decision making during transmitting.

${ }^{13}$ The setting for the confessions in this previous study involved a person admitting to having committed some
} 
messages iii) I told the truth, and message iv) I told the truth. Please trust me, meaning that some liars will tell a lie repeatedly.

Generally, cheap talk scripts used in games are conducted before the monetary payoff is decided because they affect each player's behavior in the experiment. For example, Crawford (1998) conducted coordination games with cheap talk and found that it had a positive effect on cooperation. With respect to a bargaining game, some studies report that cheap talk has a positive effect for bargainers (Valley et al., 1998; Boles et al., 2000; Croson et al., 2003), whereas some studies do not report this effect (Forsythe et al., 1991). However, because the player who decided the monetary payoff in the deception game was the receiver and we wanted to research liars' voluntary behavior, second messages as cheap talk were used after the game.

\section{Estimation model}

Here we use logit model regression in Model 1 of analyzing senders' lying behavior and in Model 2 of receivers who are practiced deception as follows:

Model 1:

$$
\begin{aligned}
\text { Lying }_{i} & =\alpha_{1}+\beta_{1} \text { Payoff }_{i k}+\gamma_{1} \text { Expectation }_{i}+\sum_{m=1} \phi_{m} \text { Socio }_{i m}+\sum_{n=1} \lambda_{n} \text { Treatment }_{i n}^{\text {Pooled }} \\
& +\varphi_{1} \text { Agreeable Im pression } \\
\text { Face } & +\eta_{1} \text { PartnerGender }_{i}^{\text {Face }}+\varepsilon_{i}
\end{aligned}
$$

Model 2:

$$
\begin{gathered}
\text { Deception }_{j}=\alpha_{2}+\gamma_{2} \text { Believe }_{j}+\sum_{m=1} \phi_{m}^{\prime} \text { Socio }_{j m}+\sum_{n=1} \lambda_{n}^{\prime} \text { Treatment }_{j n}^{\text {Poled }} \\
+\varphi_{2} \text { Agreeable Im pression }_{j}^{\text {Face }}+\eta_{2} \text { PartnerGender }_{j}^{\text {Face }}+\varepsilon_{j}^{\prime}
\end{gathered}
$$

where Lying is a dummy variable indicating lying behavior of individual $i$ as a sender. Payoff is the monetary payoff $k$ for individual $i$. Expectation is a dummy variable indicating an expectation of individual $i$ that a receiver believes the message to be true. Socio is a variable indicating the socioeconomic characteristics $k$ of individual $i$. Treatment is a dummy variable indicating each treatment $l$ by individual $i$. This variable is used in Pooled data only. Agreeable Impression and Partner Gender are dummy variables indicating an agreeable impression of a receiver and partner's gender for individual $i$, respectively. Both of them are used in F1000 treatment only. Deception is a dummy variable indicating individual $j$ who is practiced deception. Believe is a dummy variable indicating individual $j$ 's belief that a sender sends a true message. Parameters to be estimated are the

transgression, often acknowledging guilt for a crime. This study provided other settings in which confessions were presumed necessary for absolution, social acceptance, freedom, or physical and mental health, predictably resulting in personally damaging consequences to the confessor. 
following: $\alpha_{1}, \alpha_{2}, \beta_{1}, \gamma_{1}, \gamma_{2}, \lambda_{n}, \lambda_{n}^{\prime}, \phi_{m}, \phi_{m}^{\prime}, \varphi_{1}, \varphi_{2}, \eta_{1}$ and $\eta_{2}$. The terms $\varepsilon_{i}$ and $\varepsilon_{j}^{\prime}$ are a random disturbance for individuals $i$ and $j(i \neq j)$, respectively.

\section{Results and Discussion ${ }^{14}$}

We conducted the laboratory experiment at Osaka University. Participants were recruited from the Osaka University campus and from among neighborhood residents from a randomly selected sample of 30,000 households around the university. ${ }^{15}$ We conducted 47 sessions with 476 participants (116

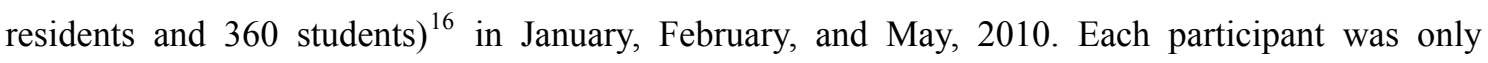
allowed to participate in one experimental session. The participants earned approximately $1500 \mathrm{JPY}$, on average. Each session lasted for approximately 35 to 60 minutes (minimum to maximum) and included between 4 and 18 persons.

\subsection{A sender's behavior}

\subsubsection{Lying behavior}

Figure 1 shows the percentage of lying behavior in each treatment. In particular, we found that the A1000-S treatment had the highest percentage of lying behavior among treatments, which is in line with results in Gneezy (2005) and Sutter (2009). In both Chi-square test and 2-sample test results for equality of proportions without continuity correction, we found that there were only significant differences between A1000-S and A1000-NS (Chi-square $=4.49, p=0.034$ ) at the $5 \%$ significance level. ${ }^{17}$ Therefore,

Result 1: Lying behavior is influenced not by the existence of partners.

This supports the economic theory that people who tell a lie to get more payoffs are rationally maximizing their utility, and this utility does not include partner information (e.g., face, build, gender). With respect to payoffs in the anonymity treatment, getting more payoffs induced lying behavior, which supports Gneezy (2005) and Sutter (2009).

The percentage of lying behavior in the face-to-face treatment is in line with that in Holm

\footnotetext{
${ }^{14}$ All data of senders and receivers in each treatment are shown in Appendix E.

15 Residents were recruited through leaflets inserted in some popular Japanese newspapers (Mainichi, Asahi, Yomiuri, and Sankei).

${ }^{16}$ The socioeconomic characteristics in all treatments are shown in Appendix D.

17 Other results are as follows: between A100-S and A100-NS (Chi-square $=0.008, p=0.923$ ), between A1000-S and A100-S (Chi-square $=2.371, p=0.124)$, between A1000-NS and A100-NS (Chi-square $=0.279, p=0.597)$, between A1000S and A100 (Chi-square $=3.581, p=0.058)$ and between A1000S and F1000 (Chi-square $=1.621, p=$ $0.203)$.
} 
and Kawagoe (forthcoming). ${ }^{18}$ As compared with studies in which the face-to-face condition indicated a difference from anonymity related to allocated pie in a dictator game (Radner and Schotter, 1989; Bohnet and Frey, 1999; Charness and Gneezy, 2008), ${ }^{19}$ this study showed that some rational behavior includes wrong ethical behavior like deception as well as equilibrium behavior as assumed by economic theory. That is, maximizing utility may not always involve ethical behavior.

Figure 1 about here

Table 2 shows the gender difference in liars between treatments. There was no significant difference between treatment and gender based on Fisher's exact test for count data.

Result 2: Lying behavior is not influenced by gender.

With respect to gender differences, Dreber and Johannesson (2008) showed that males are significantly more likely than females to lie in a deception game, which a monetary payoff was used $\{$ Sender: Receiver $\}=\{$ Option A; SEK 40:SEK 50, Option B; 50:40 $\}$. In our results, a gender difference was not different between treatments. This is in line with a psychological study (Tyler et al., 2006) which found that there are insignificant gender differences. Our results imply that males and females are likely to behave similarly (Eagly, 1987). However, since gender differences depend on culture (Gneezy et al., 2008; Croson and Gneezy, 2009) and hormones (Chen et al., 2005; Kosfeld et al., 2005; Van den Bergh and Dewitte, 2006), they should be researched further.

Table 2 about here

\subsubsection{The second messages of liars}

Figure 2 shows the percentage of second messages from liars in each treatment. ${ }^{20}$ Among treatments,

\footnotetext{
18 The results in Holm and Kawagoe (forthcoming) showed that the average percentage of lying behavior in the face-to-face condition was approximately 40 percent and 35 percent in Japan and Sweden, respectively.

${ }_{19}$ There are several studies that have compared anonymity and face-to-face conditions indirectly. For example, bargaining failures in Nydegger and Owen (1975), who conducted a face-to-face experiment, were far less than in a similar anonymous bargaining experiment (Roth and Malouf, 1982). Similarly, the face-to-face bargaining in Hoffman and Spitzer (1982) was less than the anonymous bargaining in Binmore et al. (1989).

${ }^{20}$ We excluded some data in each second message which was not written in the second questionnaire as follows: "No message" was based on the following reasoning: 1) I do not need to send a second message and 2) I do not apologize
} 
there was a significant difference between A1000-S and F1000 only (Fisher's exact test, $p=$ 0.037). ${ }^{21}$ Although a statistical test does not make clear which emotions liars feel, the number of Messages i) and ii) admitting guilt in the face-to-face treatment was larger than in the anonymity treatment.

Result 3: Liars' feelings about lying are influenced by the existence of partners, implying that this prompts liars to confess their lying behavior because they may feel remorse or guilt.

Because this was a one-shot deception game and almost all pairs were strangers in the face-to-face treatment, ${ }^{22}$ liars did not need to maintain the relationship in the future. However, some liars confessed their lying behavior. Why did they confess? Generally, confession often happens when suspects are interviewed at a police station in an effort to lessen their criminal punishment (Gudjonsson and Petursson, 1991). ${ }^{23}$ In this study, there was no punishment. Confession in this study may have meant that liars wanted to avoid feeling guilty about lying afterward. This differs from decision makers avoiding lying because they feel guilt beforehand (Charness and Dufwenberg, 2006). In addition, liars may want to ask forgiveness because of concern for their mental health (Kassin and Gudjonsson, 2004). Determining whether this line of thought is valid requires further research.

Figure 2 about here

\subsubsection{Robustness by logit regression results on lying}

Table 2 shows logit regression results in Model 1 in Pooled, ${ }^{24}$ A1000-S, A100, ${ }^{25}$ and F1000, in which the dependent variable was whether senders told a lie.

Only the variable Payoff was estimated to have significantly positive signs in all, which implies that people get more payoffs by telling a lie. This is in line with results in Gneezy (2005) and

for lying; I did not lie repeatedly. Second Messages i) and ii) were based on the following reasons: 1) to apologize for lying and 2) to excuse lying. Second Messages iii) and iv) were based on the following reasons:1) to make receivers believe the message to be true, and 2) to lie to cover up another lie.

${ }^{21}$ Other statistical results among the second messages were as follows: A1000-S $(p=1.000)$, A1000-NS $(p=1.000)$, A100-S $(p=1.000)$, A100-NS $(p=0.200)$, F1000 $(p=1.000)$, between A1000-S and A1000-NS $(p=0.200)$ and between A100-S and A100-NS $(p=0.400)$.

${ }^{22}$ Approximately $88 \%$ of pairs in the face-to-face condition were strangers to each other.

${ }^{23}$ Gudjonsson and Petursson (1991) indicated that there are three primary factors associated with criminals making confessions during interrogation based on a study of 74 criminals serving prison sentences in Iceland.

${ }^{24}$ Pooled data were excluded data in A1000-NS because of statistical results.

25 A100 was pooled data in both A100-S and A100-NS because of statistical results between treatments. 
Sutter (2009). The other variables were not estimated to be significant. That is, the variables Gender, Student and Partner's Gender were insignificant, which supports the statistical results on gender and student. As compared with A1000-S as baseline, the variables A100 and F1000 were insignificant, which supports both statistical results. In F1000, the variables Expectation and Agreeable Impression were also insignificant. This implies that having a partner does not influence liars even though they have met them directly. ${ }^{26}$ These results show the robustness of Results 1, 2, and 3.

Table 3 about here

\subsection{A receiver's behavior ${ }^{27}$}

We analyzed which factors influenced the behavior of the receivers who acted based on deception, meaning that they were told a lie from the sender in the pair and then followed their message. Regarding a treatment effect, Table 3 shows logit regression results in A1000-S and F1000.

The variable Believe was estimated to have a significantly positive sign in A1000-S, which implies that the receivers who were deceived overestimated not being lied to by a stranger. The variable Agreeable Impression was estimated to have a significantly negative sign in F1000, which implies that receivers who were deceived did not have an agreeable impression of the other person in the pair. With respect to socioeconomic characteristics, the variables Gender and Partner Gender were not estimated to be significant. This implies that gender was not an influence. Therefore,

Result 4: The receivers who were deceived believed their partners to be trustworthy in the anonymity treatment. They did not have an agreeable impression of liars in the face-to-face condition.

The first result infers that people overestimate the chances of not being deceived by a stranger. Interestingly, why did some receivers trust their partners in the anonymity treatment? One explanation is that trusting partners may be related to risk (Snijders and Keren, 1998; Ben-Ner and Putterman, 2001; Bohnet and Zeckhauser, 2004; Eckel and Wilson, 2004) ${ }^{28}$ in the sense that one does not deceive someone unknown. ${ }^{29}$ However, we cannot examine the relationship between risk

\footnotetext{
${ }^{26}$ Total percentage of an acquaintance or friend was $8 \%(3 / 37)$ in the face-to-face treatment.

27 Approximately $76 \%$ of the receivers followed the sender's message, consistent with results in Gneezy (2005) and Sutter (2009).

${ }^{28}$ Ashraf et al. (2003) showed that trust is not related to risk. However, because Eckel and Wilson (2004) found both results, a relationship between risk and trust may depend on the risk preference measured (Bohnet and Zeckhauser, 2004).

${ }^{29}$ Some receivers indicated this in the questionnaire.
} 
and trust in a deception game because risk preference was not measured in this study. In the future, this line of thought can provide a new implication on trusting others and deception.

Table 3 about here

\section{Conclusion}

This study investigated lying behavior of people who practiced deception, using a deception game under several conditions. In addition, we examined how liars feel about their lying behavior by using new messages from the sender to the receiver after the game. The results imply that the existence of partners for liars prompts them to confess lying because they may feel remorse or guilt. Furthermore, people who are deceived overestimate the chances of not being deceived by a stranger.

The results for lying behavior are in line with previous studies, which support rational behavior as which the economic theory assumes agent. Our results including previous studies showed that lying behavior was a kind of rational one due to economic theory and that the rational behavior involves ethically wrong behavior such as deception as well as equilibrium behavior. For example as other ethically wrong behavior, Falk and Fischbacher (2002) investigated the relation between criminal activity (i.e., stealing money) and social interaction in an anonymity condition and found that subjects steal the more, the more others steal, on average.

Second messages reflecting liars' feelings were different between the anonymity and face-to-face treatments. However, we did not determine which emotion liars felt most often about lying. Because behavior and emotion differed between treatments, this may indicate a change in consciousness. If liars' emotions were rational, as is lying behavior, liars would not have sent a message in both the anonymity and face-to-face treatments. Moreover, liars and their partners did not need to have a relationship during and after the experiment because the deception game was a one-shot study. Therefore, it is possible that this result provides a different definition of guilty aversion, meaning that liars avoid feeling guilty after lying because some may start to feel remorse or guilt because of the existence of partners. Moreover, the reason is possible that liars may want to ask forgiveness because of concern for their mental health (Kassin and Gudjonsson, 2004).

\section{Acknowledgements}

We would like to acknowledge the financial support provided by Grant-in-Aid for Young Scientists (Start-up) and by the Japanese Ministry of Education, Culture, Sports, Science and Technology (the 
Global COE Program of Human Behavior and Socioeconomics Dynamics). We would also like to thank several participants who suggested in ESA International Meeting 2010, Ayako Kondou, Fumio Ohtake for their helpful comments. The assistance of Katsuyuki Aoki, Kensuke Hagiwara, and Shizuru Yamagiwa in conducting the experiment is also greatly valued. 


\section{References}

Abeler, J., J. Calaki, K. Andree, and C. Basek, 2010, The power of apology. Economics Letters 107: 233-235.

Ashraf, N., I. Bohnet, and N. Piankov, 2003, Is trust a bad investment? Working paper, Kennedy School of Government, Harvard University.

Ben-Ner, A., and L. Putterman, 2001, Trusting and trustworthiness. Boston University Law Review 81: 523-551.

Binmore, K., A. Shaked, and J. Sutton, 1989, An outside option experiment. Quarterly Journal of Economics 104: 753-770.

Bochet, O., T. Page, and L. Putterman, 2006, Communication and punishment in voluntary contribution experiments. Journal of Economic Behavior \& Organization 60: 11-26.

Bohnet, I., and B. Frey, 1999, Social distance and other-regarding behavior: comment. American Economic Review 89: 335-340.

Bohnet, I., and R. Zeckhauser, 2004, Trust, risk and betrayal. Journal of Economic Behavior and Organization 55: 467-484.

Boles, T. L., R. T. A. Croson, and J. K. Murnighan, 2000, Deception and retribution in repeated ultimatum bargaining. Organizational Behavior and Human Decision Processes 83(2): 235-259.

Bottom, W. P., K. Gibson, S. E. Daniels, and J. K. Murnighan, 2002, When talk Is not cheap: Substantive penance and expressions of intent in rebuilding cooperation. Organization Science 13 (5):497-513.

Brandts, J., and G. Charness, 2003, Truth or consequences: an experiment. Management Science 49: 116-130.

Brosig, J., A. Ockenfels, and J. Weimann, 2003, The effect of communication media on cooperation. German Economic Review 4: 217-242. 
Charness, G., and M. Dufwenberg, 2006, Promises and partnership. Econometrica 74: 1579-1601.

Charness, G., and U. Gneezy, 2008, What's in a name? Anonymity and social distance in dictator and ultimatum games. Journal of Economic Behavior \& Organization 68: 29-35.

Chen, Y., P. Katuscak, and E. Ozdenoren, 2005, Why can't a woman bid more like a man? Working Paper. University of Michigan.

Crawford, V. P., 1998, A survey of experiments on communication via cheap talk. Journal of Economic Theory 78: 286-298.

Croson, R., T. Boles, and J. K. Murnighan, 2003, Cheap talk in bargaining experiments: lying and threats in ultimatum games. Journal of Economic Behavior \& Organization 51: 143-159.

Croson, R., T. and U. Gneezy, 2009, Gender differences in preferences. Journal of Economic Literature 47 (2) :1-27.

DePaulo, B, M., D. A. Kashy, S. Kirkendol, M. Wyer, and J. A. Epstein, 1996, Lying in everyday life. Journal of Personality and Social Psychology 70(5): 979-95.

Dreber A., and M. Johannesson, 2008, Gender differences in deception. Economics Letters 99 : 197-199.

Eagly, A. H., 1987, Sex differences in social behavior. A social role interpretation. Hillsdale, NJ: Erlbaum.

Eckel, C. C., and R. K. Wilson, 2004, Is trust a risky decision? Journal of Economic Behavior \& Organization 55 (4): 447-465.

Ekman, P., 1992, Telling Lies: Clues to deceit in the marketplace, politics, and marriage.. New York: W. W. Norton \& Comapany.

Ekman, P. 1989, Why Lies Fail And What Behavior Betray A lie. In J.C. Yuille (Ed.) Credibility Assessment, Dordrecht, The Netherlands: Kluwer, pp. 71-81.

Ekman, P., and W. V. Friesen, 1969, Nonverbal leakage and clues to deception. Psychiatry 32: 
$88-106$.

Ekman, P., W.V. Friesen and M. O'Sullivan, 1988, Smiles when lying. Journal of Personality and Social Psychology 29:288-298.

Falk, A., and U. Fischbacher, 2002, "Crime" in the lab: Detecting social interaction. European Economic Review 46: 859-869.

Fischbacher, U. and V. Utikal, 2010, On the acceptance of apologies. Research paper Series No.53, the University of Konstanz.

Ford, C. V., 1995, Lies! Lies! Lies! The psychology of deceit. Washington, DC: American Psychiatric Press, Inc.

Forsythe, R., J. Kennan, and B. Sopher, 1991, An experimental analysis of strikes in bargaining games with one-sided private information. American Economic Review 81: 253-278.

Frohlich, N., and J. Oppenheimer, 1998, Some consequences of e-mail versus face-to-face communication in experiment. Journal of Economic Behavior and Organization 35: 389-403.

Gibson, K., W. Bottom, and K. Murnighan, 1999, Once bitten: defection and reconciliation in a cooperative enterprise. Business Ethics Quarterly 9: 69-85.

Gneezy, U., 2005, Deception: The role of consequences. American Economic Review 95: 384-394.

Gneezy, U., L. L. Kenneth, and J. A. List, 2006, Gender differences in competition: Evidence from a matrilineal and a patriarchal society. NBER Working paper 13727.

Gudjonsson, G.H., and H. Petursson, 1991, Custodial interrogation: Why do suspects confess and how does it relate to their crime, attitude and personality? Personality and Individual Differences 12 : 295-306.

Ho, B., 2007, Apologies as signals: With evidence from a trust game, Cornell University Discussion Paper.

Hoffman, E., and M. Spitzer, 1982, The Coase theorem: some experimental tests. Journal of Law and 
Economics 25: 73-98.

Holm, H., and T. Kawagoe, (forthcoming), Face-to-face Lying - An experimental study in Sweden and Japan. Journal of Economic Psychology.

Hurkens, S., and N. Kartik, 2009, Would I lie to you? On social preferences and lying aversion. Experimental Economics 12: 180-192.

Hwang, P., 2006, Asset specificity and the fear of exploitation. Journal of Economic Behavior \& Organization 60: 423-438.

Isaac, R.M., and J.M. Walker, 1988, Communication and free-riding behavior: the voluntary contributions mechanism. Economic Inquiry 26: 585-608.

Kassin, S. M., and G. H. Gudjonsson, 2004, The psychology of confessions: A review of the literature and issues. Psychological Science in the Public Interest 5: 35-67.

Kim, P., D. Ferrin, C. Cooper, and K. Dirks, 2004, Removing the shadow of suspicion: the effects of apology versus denial for repairing competence- versus integrity-based trust violations. Journal of Applied Psychology 89: 104-118.

Kosfeld, M., M. Heinrichs, P. J. Zak, U. Fischbacher, and E. Fehr, 2005, Oxytocin increases trust in humans. Nature 435: 673-676.

Lundquist, T., T. Ellingsen, E. Gribbe, and M. Johannesson, 2009, The aversion to lying. Journal of Economic Behavior \& Organization 70: 81-92.

Nydegger, R., and G. Owen, 1975, Two person bargaining: an experimental test of the Nash axioms. International Journal of Game Theory 3: 239-349.

Radner, R., and A. Schotter, 1989, The sealed bid mechanism: an experimental study. Journal of Economic Theory 48: 179-220.

Roth, A., 1995, "Bargaining Experiments," in the Handbook of Experimental Economics, ed. by J. Kagel and A. Roth. Princeton, NJ: Princeton University Press, pp.253-348. 
Roth, A., and M. Malouf, 1982, Scale changes and shared information in bargaining: an experimental study. Mathematical Social Sciences 3: 157-177.

Sanchéz-Pages, S., and M. Vorsatz, 2007, An experimental study of truth-telling in a sender-receiver game. Games and Economic Behavior 61: 86-112.

Sanchéz-Pages, S., and M. Vorsatz, 2009, Enjoy the silence: an experiment on truth-telling. Experimental Economics 12: 220-241.

Schweitzer, M. E., J. C. Hershey, and E. T. Bradlow, 2006, Promises and lies: Restoring violated trust. Organizational Behavior and Human Decision Processes 101 (1): 1-19.

Snijders, C., and G. Keren, 1998, Determinants of trust. In: Budescu, D.V., Erev, I., Zwick, R. (Eds.), Games and Human Behavior: Essays in Honor of Amnon Rapoport. Lawrence Erlbaum, Mahwah, NJ, pp. 355-385.

Sutter, M., 2009, Deception through telling the truth?! Experimental evidence from individuals and teams. Economic Journal 119: 47-60.

Turvey, C. G., B. Onyango, C. Cuitec, and W. K. Hallman, 2010, Risk, fear, bird flu and terrorists: A study of risk perceptions and economics. The Journal of Socio-Economics 39: 1-10.

Tyler, J.M., R. S. Feldman, and A. Reichert, 2006, The price of deceptive behavior: disliking and lying to people who lie to us. Journal of Experimental and Social Psychology 42: 69-77.

Valley, K. L., J. Moag, and M. H. Bazerman, 1998, A matter of trust: effects of communication on the efficiency and distribution of outcomes. Journal of Economic Behavior \& Organization 34: 211-238.

Van den Bergh, B., and S. Dewitte, 2006, Digit ratio (2D:4D) moderates the impact of sexual cues on men's decisions in ultimatum games. Proceedings of the Royal Society B 273: 2091-2095.

Vrij, A., 2001, Detecting lies and deceit: The psychology of lying and the implications for professional practice. New York: John Wiley \& Sons. 


\section{Appendix:}

Appendix A: Instructions (original text in Japanese) [with changes for face-to-face treatment]

\section{A.1. Instructions for Role A as a sender}

There are instructions and two kinds of messages, A and B, in the "Message 1" envelope. First, please check the envelope for these. Next, we will explain the procedure in depth.

\section{Overview}

In the experiment, one person in this room and one person in another room will interact with each other. Both of them are randomly assigned to one of two possible roles: either Role A or Role B. First, Role A will send a message to Role B. Next, Role B will choose a monetary payment option after Role B has received the message from Role A. The monetary payments for both Roles A and B in the experiment depend on the choice of Role B.

Please read the instructions carefully. Do not talk or in any way try to communicate with other participants during the experiment. The earnings are calculated by summing the monetary payment in the experiment and the show-up fee (500 JPY). You will be paid privately and in cash at the end of the experiment.

\section{Your role}

Your role in this experiment is Role A. Role B, with whom you will be paired in the experiment, is in another room. You will send either Message 1 or 2 to Role B. [Eliminating the following sentence: No information about your partner will be provided to you during or after the experiment.] At the end of the experiment, you will not meet Role B.

\section{Alternatives}

Two possible monetary payments are available to Role A and Role B in the experiment. The two payment options are as follows:

In Treatment A1000-S, A1000-NS and F1000:

Option A: 500 JPY to Role A and 1500 JPY to Role B

Option B: 1500 JPY to Role A and 500 JPY to Role B

In Treatment A1000-S and A1000-NS:

Option A: 900 JPY to Role A and 1000 JPY to Role B 
Option B: 1000 JPY to Role A and 900 JPY to Role B

Role B will have to choose either option A or option B. The only information Role B will have is information sent by you in a message. That is, Role B will not know the monetary payments associated with each choice.

\title{
Message
}

We now ask you to choose one of the following two possible messages which you will send to Role B:

\begin{abstract}
Message 1: "Option A will earn you more money than option B."
Message 2: "Option B will earn you more money than option A."
\end{abstract}

\section{How to send a message to Role B}

In the "Message" envelope you are provided with two cards. On one is written Message 1, and Message 2 is written on the other. You will choose one of the two messages and then enclose that card in the "Message" envelope. You will put the card you do not choose on the desk. After all Role A participants finish doing this, the experimenters will collect the "Message" envelope and provide the selected message to Role B in each pair.

[In the "Message" envelope you are provided with two cards. On one is written Message A, and Message B is written on the other. You provide this "Message" envelope to Role B directly. First, you go out carrying two messages in the "Message" envelope when the experimenters signal. Role B goes out simultaneously. Next, you will choose one of the two messages and enclose the card on which it is written in the "Message" envelope at the table with partitions. You lay the card which you do not choose face down. If you want to check the instructions, please read the instructions affixed to the partitions. Last, you provide the "Message" envelope to Role B with whom you stand face to face. After you do this, please go back to your seat. Please do not speak to Role B during this time.]

\section{Earnings}

Role B chooses one of two alternatives, Option A or B, after Role B receives the message from Role A. The monetary payments for Roles A and B depend on this choice. The earnings are calculated by summing the monetary payment in the experiment and the show-up fee (500 JPY). You will be paid privately and in cash at the end of the experiment.

To repeat, you can know the monetary payments for both yourself and Role B. However, Role B will never know what sums were actually offered in the option not chosen (that is, he or she will never 
know whether your message was true or not). Moreover, Role B will never know the sums to be paid to you according to the different options.

If you have any questions, please raise your hand quietly. The experimenters will answer them privately.

\section{A.2. Instructions for Role B as a receiver}

There are instructions and two kinds of messages, A and B, in the "Message" envelope. First, please check the envelope for these. Next, we will explain the procedure in depth.

\section{Overview}

In the experiment, one person in this room and one person in another room will interact with each other. Both of them are randomly assigned to one of two possible roles: either Role A or Role B. First, Role A will send a message to Role B. Next, Role B will choose a monetary payment option after Role B has received the message from Role A. The monetary payments for both Roles A and B in the experiment depend on the choice of Role B.

Please read the instructions carefully. Do not talk or in any way try to communicate with other participants during the experiment. The earnings are calculated by summing the monetary payment in the experiment and the show-up fee (500 JPY). You will be paid privately and in cash at the end of the experiment.

\section{Your role}

Your role in this experiment is Role B. Role A, with whom you will be paired in the experiment, is in another room. You will choose one of two alternatives, Option A or B. [Eliminating the following sentence: No information about your partner will be provided to you during or after the experiment.] At the end of the experiment, you will not meet Role A.

\section{Alternatives}

Two possible monetary payments are available to Role A and Role B in the experiment. Role B will have to choose either Option A or Option B. The only information Role B will have is information sent by Role A in a message. That is, Role B will not know the monetary payments associated with each choice.

\section{Message}

We now ask you, Role A, to choose one of the following two possible messages, which you will 
send to Role B:

$$
\begin{aligned}
& \text { Message 1: "Option A will earn you more money than option B." } \\
& \text { Message 2: "Option B will earn you more money than option A." }
\end{aligned}
$$

One of the two messages, either Message 1 or Message 2, in the "Message" envelope from Role A is provided by the experimenter.

[One of the two messages, either Message 1 or Message 2 in the "Message" envelope from Role A is provided by the experimenter. First, you go out when the experimenters signal. Role A goes out simultaneously. Next, you will receive the "Message" envelope from Role A after Role A chooses one of the two messages, 1 or 2, and then encloses the card on which it is written in the "Message" envelope at the table with partitions. After you do this, please go back to your seat. Please do not speak to Role A during this time.]

\section{How to send an alternative to Role $A$}

You will choose one of the two alternatives, Option A or B, after you receive the message. You are provided cards on which are written two alternatives, Options 1 and 2, in the "Decision" envelope. You will choose one of the two alternatives and then enclose that card in the "Decision" envelope. You will put the card you do not choose on the desk. After all Role B participants finish doing this, the experimenters will collect the "Decision" envelope and provide the selected alternative to Role A in each pair.

\section{Earnings}

You choose one of two alternatives, Option A or B, after you receive the message from Role A. The monetary payments for Roles $\mathrm{A}$ and $\mathrm{B}$ depend on this choice. The earnings are calculated by summing the monetary payment in the experiment and the show-up fee (500 JPY). You will be paid privately and in cash at the end of the experiment.

To repeat, Role A will know the monetary payments for both you and Role A when Role A chooses a message. However, you will never know what sums were actually offered in the option not chosen (that is, you will never know whether the message from Role A was true or not during and after the experiment). Moreover, you will never know the sums to be paid to you according to the different options.

If you have any questions, please raise your hand quietly. The experimenters will answer them privately. 
Appendix B: Questionnaires

\section{B.1. Questionnaire for Role A as a sender}

B.1.1. First questionnaire [in face-to-face treatment]

Please respond to the following.

[1. About Role B in the pair:

A: I have never seen him/her before.

B: I have seen but never talked to him/ her.

C: I just exchange greetings with him/her.

D: I talk with him/ her sometimes.

E: I often talk with him/her; he/she is a good friend of mine.

2. How do you feel about Role B?
A: Very good
B: Good
C: Neither good nor bad
D: Not very good
E: Not good at all]

3. Do you expect Role B to believe your message is true?
A: Role B will always believe it is true.
B: Role B will sometimes believe it is true.
C: Don't know
D: Role B will sometimes not believe it is true.
E: Role B will never believe it is true.

4. Which option do you expect Role B to choose?
A: Option A
B: Option B

\section{B.1.2. Second questionnaire}

Please answer the following questions. 
1. Did you send a message to Role B?
A: Yes $\rightarrow$ To question 2
$\mathrm{B}: \mathrm{No} \rightarrow$ To question 3

2. (For individuals who chose answer A in question 1) What kind of message did you send?

i) I told a lie. I am sorry.

ii) I told a lie because there was a reason.

iii) I told the truth.

iv) I told the truth. Please believe me.

Reason:

3. (For individuals who chose answer B in question 1 ) Why did you not send a message? Reason:

B.2. Questionnaire for Role B as a receiver

\section{B.2.1. First questionnaire [in face-to-face treatment]}

Please respond to the following.

[1. About Role A in the pair:
A: I have never seen him/her before.
B: I have seen but never talked to him/ her.
$C$ : I just exchange greetings with him/her.
D: I talk with him/ her sometimes.
E: I often talk with him/her, he/she is a good friend of mine.

2. How do you feel about Role A?
A: Very good
B: Good
C: Neither good nor bad
D: Not very good
E: Not good at all]

3. Do you believe the message from Role A to be true? 

A: I absolutely believe it to be true.
B: I sometimes believe it to be true.
C: Don't know
D: I sometimes do not believe it to be true.
E: I never believe it to be true.

\section{B.2.2. Second questionnaire}

Please check the message in the "Message 2" envelope and answer the following questions:

1. What kind of message did you receive?

The message:

2. Do you believe the message from Role A to be true?
A: I absolutely believe it to be true.
B: I sometimes believe it to be true.
C: Don't know
D: I sometimes do not believe it to be true.
E: I never believe it to be true. 
Appendix C: Second message instructions for Role A

There are instructions, the alternative from Role B, and four kinds of other messages, i, ii, iii and iv, in the envelope.

First, please check the envelope for these.

Next, we will explain the messages in depth. It is possible for you to send or not send a message to Role B. When one sends a message, it is chosen from among the following four messages written on cards:

i) I told a lie. I am sorry.

ii) I told a lie because there were reasons.

iii) I told the truth.

iv) I told the truth. Please trust me.

Last, one who wants to send a message encloses it in the "Message 2" envelope and all other messages are put in the first envelope that was used. One who does not send a message encloses all the messages in the first envelope. Then, the experimenters will collect them and send the "Message 2" envelope to Role B in each pair. 
Appendix D: Socioeconomic characteristics

\begin{tabular}{|c|c|c|c|c|c|c|}
\hline Variables & Definition & A1000-S & A1000-NS & A100-S & A100-NS & F1000 \\
\hline Gender & $\begin{array}{l}\text { A dummy variable }=1 \text { if a } \\
\text { participant is female. }\end{array}$ & $\begin{array}{r}0.432 \\
(0.042)\end{array}$ & $\begin{array}{r}0.852 \\
(0.049)\end{array}$ & $\begin{array}{c}0.377 \\
(0.056)\end{array}$ & $\begin{array}{r}0.694 \\
(0.059)\end{array}$ & $\begin{array}{c}0.444 \\
(0.042)\end{array}$ \\
\hline Age & Age in years. & $\begin{array}{l}20.714 \\
(0.222)\end{array}$ & $\begin{array}{l}47.741 \\
(1.822)\end{array}$ & $\begin{array}{c}20.83 \\
(0.295)\end{array}$ & $\begin{array}{l}47.270 \\
(1.635)\end{array}$ & $\begin{array}{l}20.183 \\
(0.159)\end{array}$ \\
\hline Occupation & $\begin{array}{l}\text { A categorical variables: } 1= \\
\text { full-time job; } 2=\text { part-time } \\
\text { job; } 3=\text { self-employed; } 4= \\
\text { housewife; } 5=\text { student. }\end{array}$ & $\begin{array}{r}5.000 \\
(0.000)\end{array}$ & $\begin{array}{c}3.481 \\
(0.188)\end{array}$ & $\begin{array}{r}5.000 \\
(0.000)\end{array}$ & $\begin{array}{c}3.302 \\
(0.193)\end{array}$ & $\begin{array}{r}5.000 \\
(0.000)\end{array}$ \\
\hline Education & $\begin{array}{l}\text { A categorical variable: } \\
\text { 1=High school; 2=College; } \\
\text { 3=University; 4=Graduate } \\
\text { school; 5=Other. }\end{array}$ & - & $\begin{array}{r}2.815 \\
(0.099)\end{array}$ & - & $\begin{array}{l}2.460 \\
(0.117)\end{array}$ & - \\
\hline Household & $\begin{array}{l}\text { A categorical variable: } 1=1 \\
\text { person; } 2=2 \text { persons; } 3=3 \\
\text { persons; } 4=4 \text { persons; } 5= \\
\text { above } 5 \text { persons. }\end{array}$ & $\begin{array}{r}2.121 \\
(0.126)\end{array}$ & $\begin{array}{c}3.019 \\
(0.148)\end{array}$ & $\begin{array}{c}2.195 \\
(0.164)\end{array}$ & $\begin{array}{c}3.333 \\
(0.138)\end{array}$ & $\begin{array}{c}2.359 \\
(0.137)\end{array}$ \\
\hline Income $^{a}$ & $\begin{array}{l}\text { A categorical variable } \\
(\mathrm{JPY}): 1=\text { under } 2,500,000 ; \\
2=2,500,000-3,999,999 ; \\
3=4,000,000-5,499,999 ; \\
4=5,500,000-6,999,999 ; \\
5=\text { above } 7,000,000 .\end{array}$ & $\begin{array}{l}2.679 \\
(0.175)\end{array}$ & $\begin{array}{l}3.852 \\
(0.199)\end{array}$ & $\begin{array}{l}3.224 \\
(0.244)\end{array}$ & $\begin{array}{c}3.730 \\
(0.196)\end{array}$ & $\begin{array}{c}3.218 \\
(0.182)\end{array}$ \\
\hline Observations & & 140 & 54 & 77 & 63 & 142 \\
\hline
\end{tabular}

Note: Numbers not in parentheses are mean values. Standard errors are in parentheses.

${ }^{a}$ Note that this variable in the experiment denotes monthly disposable income besides room rental expenses. 
Appendix E: Descriptive statistics both senders and receivers

\begin{tabular}{cccccccc}
\hline Sender & Receiver & A1000-S & A1000-NS & A100-S & A100-NS & F1000 & Total \\
\hline Message 1 & Option A & 22 & 20 & 18 & 17 & 30 & 107 \\
(True) & Option B & 14 & 0 & 7 & 5 & 14 & 40 \\
& & & & & & & \\
Message 2 & Option A & 11 & 1 & 3 & 5 & 7 & 27 \\
(Lie) & Option B & 23 & 6 & 10 & 5 & 20 & 64 \\
& & & & & & & \\
Observation & & 70 & 27 & 38 & 32 & 71 & 238 \\
\hline
\end{tabular}


Figure 1. Percentage of senders who told the lie in each treatment

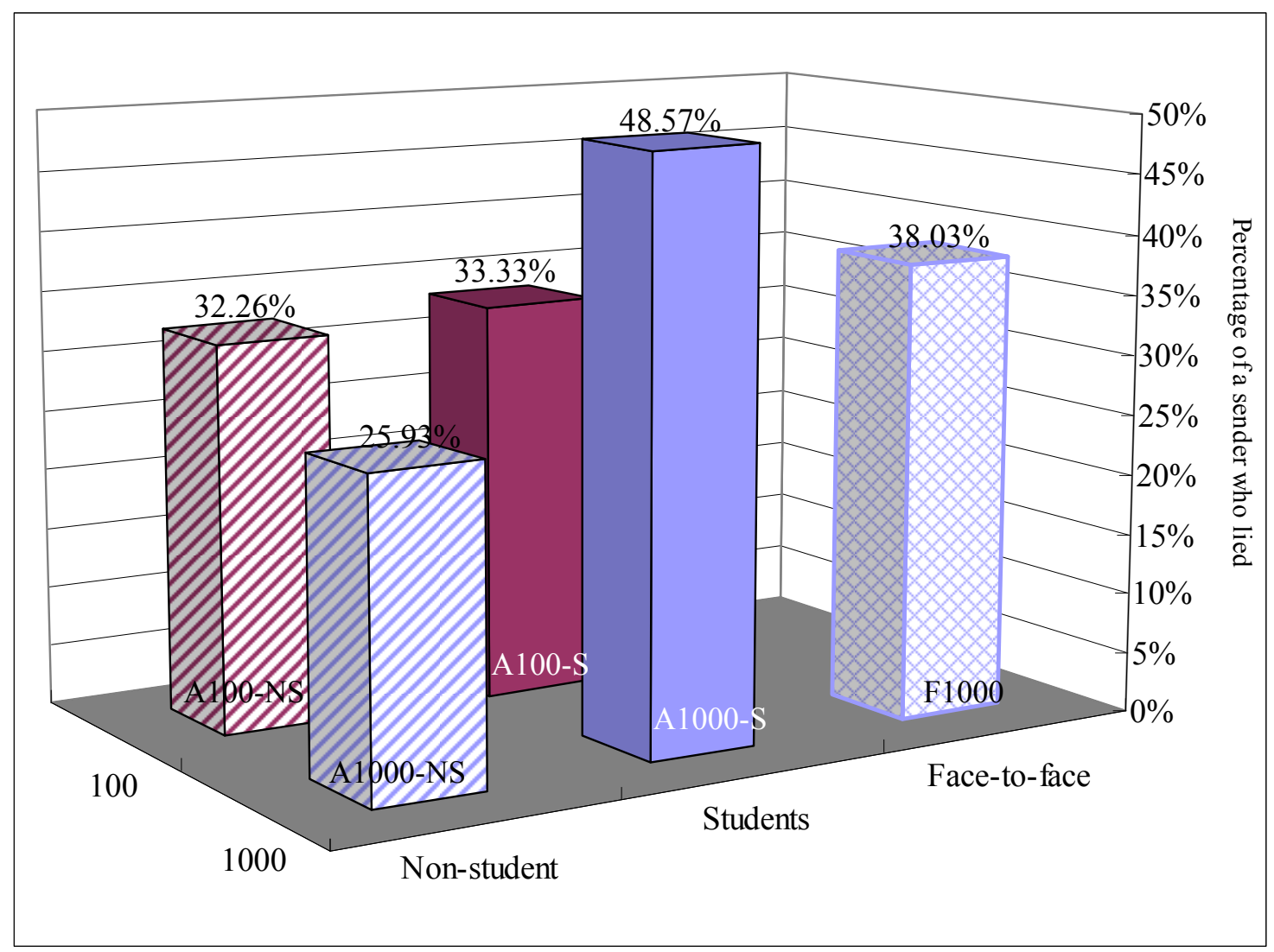


Figure 2. The number of second messages in which a sender lied in each treatment

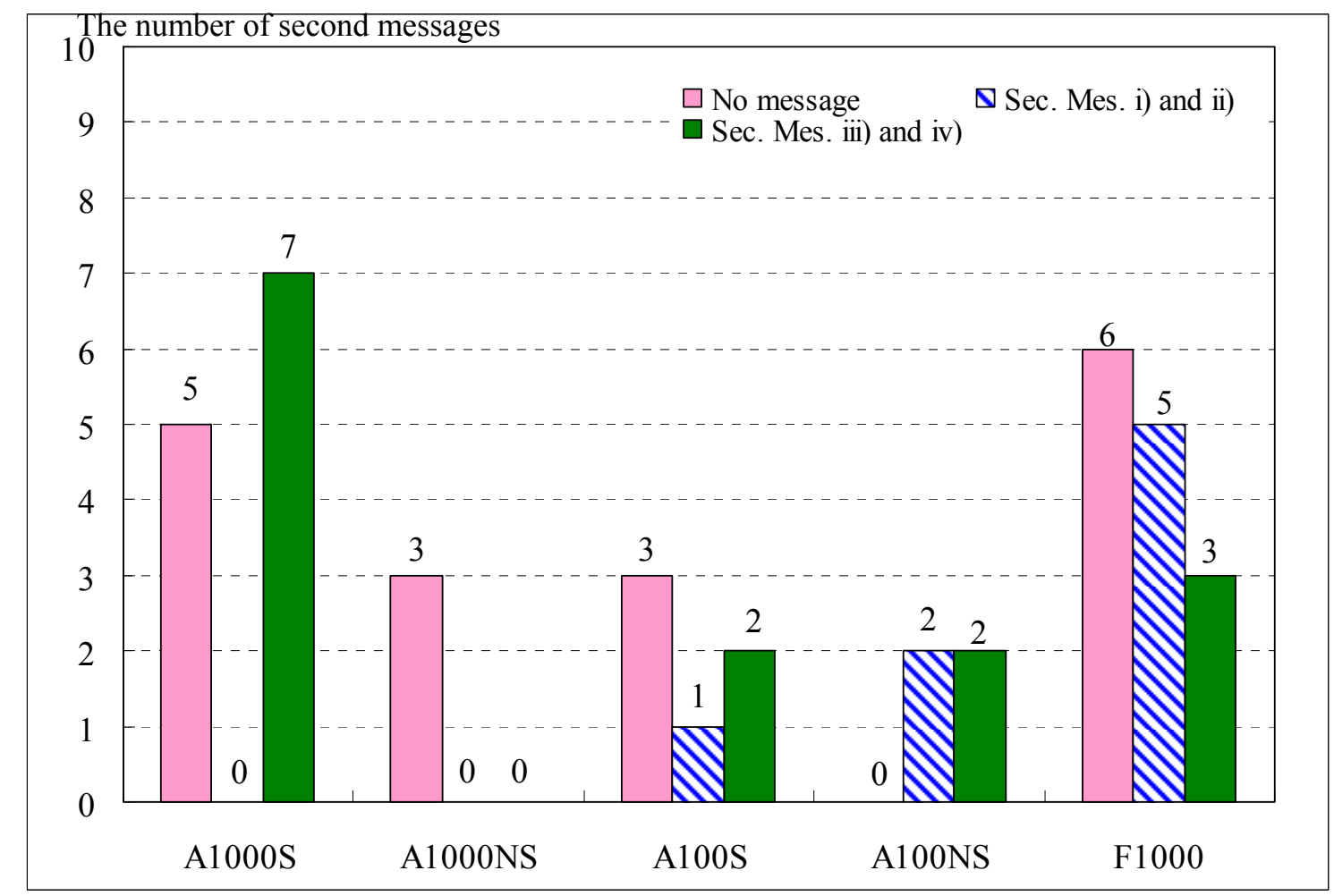

Notes: "No message" means that the sender does not send any message after the alternative chosen by the receiver is provided. Not sending a second message is based on the following reasons: I do not need to send a second message, I do not apologize for lying, and I did not lie repeatedly. Second Messages i) and ii) are sent to either apologize for lying or to excuse lying. Second Messages iii) and iv) are sent to make receivers believe the message is true or to lie to cover up another lie. Data for other reasons provide that are not choices in the second questionnaire are excluded here. 
Table 1. Treatments and payoffs (in JPY) in treatments

\begin{tabular}{|c|c|c|c|}
\hline Treatment & \multicolumn{2}{|c|}{ Anonymity } & Face-to-face \\
\hline Student & A100-S & A1000-S & F1000 \\
\hline Non-student & A100-NS & A1000-NS & - \\
\hline
\end{tabular}

Notes: the payoff is derailed as follows:

\begin{tabular}{|c|c|c|c|}
\hline Payoff & Option & Sender & Receiver \\
\hline \multirow{2}{*}{100} & $\mathrm{~A}$ & 900 & 1000 \\
\cline { 2 - 4 } & $\mathrm{B}$ & 1000 & 900 \\
\hline \multirow{2}{*}{1000} & $\mathrm{~A}$ & 500 & 1500 \\
\cline { 2 - 4 } & $\mathrm{B}$ & 1500 & 500 \\
\hline
\end{tabular}

Table 2. The percentage of gender different of liars between treatments

\begin{tabular}{ccccccc}
\hline Sender & A1000-S & A1000-NS & A100-S & A100-NS & F1000 & Total \\
\hline Male & 26.6 & 25.0 & 16.7 & 15.8 & 17.7 & 20.6 \\
& $(21 / 79)$ & $(2 / 8)$ & $(8 / 48)$ & $(3 / 19)$ & $(14 / 79)$ & $(48 / 233)$ \\
Female & 21.7 & 10.9 & 17.2 & 16.2 & 20.6 & 17.8 \\
& $(13 / 60)$ & $(5 / 46)$ & $(5 / 29)$ & $(7 / 43)$ & $(13 / 63)$ & $(43 / 241)$ \\
Each treatment (p-value) & 0.554 & 0.275 & 1.000 & 1.000 & 0.673 & \\
Between treatments (p-value) & \multicolumn{2}{c}{0.209} & & 0.214 & $0.603^{\text {a }}$ & \\
No. liars & 34 & 7 & 13 & 10 & 27 & 91 \\
\hline
\end{tabular}

Notes: ${ }^{a}$ shows the statistical result between A1000-S and F1000 treatments. 
Table 3. Logit regression results on lying behavior of senders

\begin{tabular}{|c|c|c|c|c|c|}
\hline Variables & Definition & Pooled $^{\mathrm{a}}$ & A1000-S & $\mathrm{A} 100^{\mathrm{b}}$ & F1000 \\
\hline \multirow[t]{2}{*}{ Constant } & & $-1.626 * *$ & -0.952 & $-17.183^{* * *}$ & $-2.805^{* * *}$ \\
\hline & & $(0.807)$ & $(0.738)$ & $(5.538)$ & $(0.954)$ \\
\hline \multirow[t]{2}{*}{ Payoff } & The earnings. & $0.002 * * *$ & $0.001 * *$ & $0.017 * * *$ & $0.002 * * *$ \\
\hline & & $(0.000)^{\mathrm{c}}$ & $(0.001)^{\mathrm{c}}$ & $(0.006)^{\mathrm{c}}$ & $(0.001)$ \\
\hline \multirow[t]{2}{*}{ Expectation } & Dummy variable $=1$ if a sender expects that & -0.024 & -0.169 & 0.062 & 0.309 \\
\hline & a receiver believes the message trust. & $(0.304)$ & $(0.520)$ & $(0.564)$ & $(0.577)$ \\
\hline \multirow[t]{2}{*}{ Gender } & Dummy variable $=1$ if a sender is female. & -0.060 & -0.458 & 0.090 & 0.436 \\
\hline & & $(0.314)$ & $(0.519)$ & $(0.654)$ & $(0.565)$ \\
\hline \multirow[t]{2}{*}{ Student } & Dummy variable $=1$ if a sender is a student. & -0.000 & & -0.121 & \\
\hline & & $(0.537)$ & & $(0.652)$ & 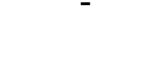 \\
\hline \multirow{2}{*}{$\begin{array}{c}\text { Treatment }^{\mathrm{d}} \text { : } \\
\text { A100 }\end{array}$} & Dummy variable $=1$ if a treatment is $\mathrm{A} 100$. & -0.499 & & & \\
\hline & & $(0.430)$ & 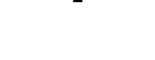 & - & 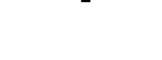 \\
\hline \multirow{2}{*}{$\begin{array}{l}\text { Treatment }^{\mathrm{d}} \text { : } \\
\text { F1000 }\end{array}$} & Dummy variable $=1$ if a treatment is & -0.413 & & & \\
\hline & F1000. & $(0.367)$ & 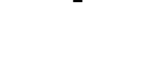 & 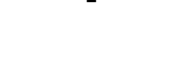 & 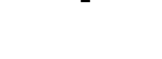 \\
\hline \multirow{2}{*}{$\begin{array}{l}\text { Agreeable } \\
\text { impression }\end{array}$} & Dummy variable $=1$ if a sender have an & & & & -0.102 \\
\hline & agreeable impression for a receiver. & - & - & - & $(0.578)$ \\
\hline \multirow[t]{2}{*}{ Partner gender } & Dummy variable $=1$ if a receiver differ & & & & 0.008 \\
\hline & from gender to a sender. & 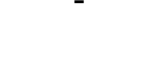 & 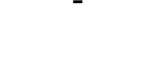 & - & $(0.574)$ \\
\hline \multicolumn{2}{|l|}{ Log-likelihood } & -130.292 & -45.143 & -39.145 & -40.558 \\
\hline \multicolumn{2}{|l|}{ McFadden's $R^{2}$} & 0.081 & 0.069 & 0.117 & 0.140 \\
\hline \multicolumn{2}{|l|}{ Observation } & 211 & 70 & 70 & 71 \\
\hline
\end{tabular}

Notes: Standard deviations are in parentheses. ${ }^{* * *}, * *$ and $*$ denote that the parameters are different from zero at $1 \%, 5 \%$ and $10 \%$ significance levels, respectively. ${ }^{a}$ is excluded data in A1000-NS because of statistical results. ${ }^{b}$ is pooled data both A100-S and A100-NS because of statistical results between treatments. ${ }^{c}$ is significantly the largest marginal effect. ${ }^{d}$ shows that the baseline treatment is A1000-S. 
Table 4. Logit regression results on behavior of receivers who are practiced deception

\begin{tabular}{clcc}
\hline Variables & \multicolumn{1}{c}{ Definition } & A1000-S & F1000 \\
\hline Constant & & $-2.162^{* * *}$ & -0.548 \\
Believe & $(0.570)$ & $(0.592)$ \\
& Dummy variable=1 if a receiver believes the & $1.616^{* * *}$ & -0.039 \\
& message to be trust. & $(0.602)^{\mathrm{a}}$ & $(0.560)$ \\
Gender & Dummy variable=1 if a receiver is female. & 0.938 & \\
& & $(0.566)$ & - \\
Agreeable & Dummy variable=1 if a receiver have an & & $-0.991^{*}$ \\
impression & agreeable impression for a sender by seeing. & & $(0.567)^{\mathrm{a}}$ \\
Gender in pair & Dummy variable=1 if gender in pair is & - & 0.583 \\
& different.. & & $(0.564)$ \\
& & -37.049 & -40.365 \\
Log-likelihood & & 0.142 & 0.044 \\
McFadden's $R^{2}$ & & 69 & 71 \\
\hline Observation & & & \\
\hline
\end{tabular}

Notes: Standard deviations are in parentheses. ${ }^{* *}, * *$ and $*$ denote that the parameters are different from zero at $1 \%, 5 \%$ and $10 \%$ significance levels, respectively. ${ }^{a}$ is significantly the largest marginal effect. 